* Professora-Pesquisadora do Programa de Mestrado da Universidade Nove de Julho, Professora do Mackenzie, Livre-Docente, Doutora e Mestre em Direito do Estado pela Faculdade de Direito da USP, por onde se graduou. E-mail: irene.nohara @uol.com.br

\section{Regulação da atividade econômica na dissolução das fronteiras entre público e privado}

\author{
REgULATION OF ECONOMIC ACTIVITY IN \\ DISSOLUTION OF BORDERS BETWEEN PUBLIC AND \\ PRIVATE \\ * Irene Patrícia Nohara
}

Resumo: A presente reflexão tem por objetivo abordar a regulação da atividade econômica no contexto de dissolução das fronteiras entre público e privado. Parte das categorias serviços públicos e poder de polícia para delimitar as intensidades de regulação desejadas pela Constituição. Objetiva-se problematizar a dissolução entre as fronteiras, num contexto de iminência de crise e escassez, no qual há, de um lado, um movimento de retração na prestação direta do Estado de serviços públicos e, de outro, a intensificação na intervenção no mercado. Enfatiza a importância da disseminação do princípio democrático, bem como a necessidade de razoabilidade dos parâmetros regulatórios.

Palavras-Chave: Regulação; Democracia; Estado; Público; Privado.

Abstract: The present paper aims to address the regulation in the context of dissolution of borders between public and private. It departs from the analysis of public services and police power to define the regulatory intensity desired by Brazilian Constitution. Then it discusses the dissolution of the boundaries in the context of impending crisis and scarcity, in which there is, in one hand, a retraction movement in direct provision of state public services and, on the other, a much more intense market intervention. It emphasizes the importance of the spread of democratic principle and the need for reasonableness from regulatory parameters.

Keywords: Regulation; Democracy; State; Public; Private. 


\section{INTRODUÇÃO}

A presente reflexão tem por objetivo abordar os fundamentos da regulação na atividade econômica no contexto das agências reguladoras como contribuição para um debate que se aperfeiçoa na relação entre Estado e Economia.

Objetiva-se inicialmente expor a sistemática constitucional acerca da atividade econômica, a partir das diferenças de tratamento que se rascunharam na doutrina entre os conceitos de regulação dos serviços públicos e de poder de polícia, para delimitar, com referencial teórico na clássica exposição de Eros Roberto Grau, algumas supostas intensidades de regulação em função da natureza da atividade regulada.

Na sequência, haverá a problematização da dissolução das fronteiras entre público e privado, sobretudo em um contexto de iminência de crise e escassez, que provoca, de um lado, a privatização do público, movimento que teve como marco o Plano Diretor de Reforma do Aparelho do Estado, inspirado na fase gerencial da New Public Management, sendo deste projeto derivada a agencificação nos serviços públicos no Brasil, e, de outro, a publicização do privado.

O movimento de publicização do privado será abordado com base em dois eixos de indagação: em primeiro lugar, a constatação de uma intensificação na regulação do mercado, que se dá em contextos de iminência de crise e obscurece a distinção entre a intensidade do planejamento desejada originariamente pela Constituição, e, de outro, a disseminação dos valores de participação e de legitimação.

Será defendido que os valores da governança corporativa, presentes nas noções de compliance, transparência (disclosure) e accountabilility, devem ser enriquecidos com a proposta de operacionalização do princípio democrático, para que haja maior intersubjetividade no conteúdo da regulação.

Tal proposta será alicerçada em duas vertentes: a abertura dos canais de expressão e de discussão do interesse público no seio das agências reguladoras, bem como a consideração de aspectos substanciais contidos na exigência de razoabilidade do conteúdo da regulação.

Espera-se contribuir com uma ênfase na importância da contraofensiva da colonização do público pelo privado, para que, num contexto de crescente escassez de recursos, haja a retomada pelo Estado de uma preocupação com o equilíbrio social e com o estímulo à sustentabilidade do desenvolvimento 
econômico, desde que tal movimento seja feito dentro de parâmetros de razoabilidade e de participação, preservando-se também o núcleo dos direitos e liberdades dos agentes econômicos.

\section{REGULAÇÃO NA SISTEMÁTICA CONSTITUCIONAL: SERVIÇOS PÚBLICOS E PODER DE POLÍCIA}

É bastante conhecida no Direito Econômico brasileiro a teorização de Eros Roberto Grau acerca da atividade econômica na obra $A$ ordem econômica na Constituição de 1988. Segundo expõe, a atividade econômica em sentido amplo é gênero, do qual decorrem duas espécies: (1) os serviços públicos, sendo estes considerados uma área em que a Constituição atribui a incumbência ou titularidade ao Poder Público, que, de acordo com a disciplina constitucional do art. 175, pode prestá-los diretamente ou por meio de concessionárias ou permissionárias; e (2) a atividade econômica em sentido estrito, também denominada mercado, em que o Estado intervém em caráter de maior excepcionalidade, nos casos explicitados no art. 173, seja em regime de livre concorrência ou em monopólio.

Segundo conceitua Grau (2006, p. 103), serviço público "é o tipo de atividade econômica cujo desenvolvimento compete preferencialmente ao setor público. Preferencialmente não significa exclusivamente, visto que o setor privado presta serviço público em regime de concessão ou permissão".

Ademais, mesmo diante da presença de concorrência entre os concessionários e permissionários, ainda assim, a área dos serviços públicos é uma área de atuação do Estado, o qual, quando não presta diretamente a atividade, regula sua prestação de forma a suprir necessidades coletivas, diferentemente da regulação que, em tese, deveria ocorrer no domínio econômico, tendo em vista o fato de vigorar neste âmbito o princípio da livreconcorrência.

Sobre o mercado recai a restrição do poder de polícia, que abrange a regulação, dado que implica na atividade do Estado de condicionar ou restringir o exercício dos direitos individuais, como a liberdade e a propriedade, em nome do interesse coletivo (BANDEIRA DE MELLO, 2014, p. 840; DI PIETRO, 2014, p. 124), ou mesmo a intervenção do Estado pela participação, por empresas estatais que desenvolvam atividades no domínio econômico.

A participação do Estado como medida de intervenção no mercado é considerada por Eros Grau como excepcional, tendo em vista o disposto no 
art. 173 da Constituição, que determina que, ressalvados os casos previstos na Constituição, a exploração de atividade econômica do Estado só é permitida diante de imperativos da segurança nacional ou relevante interesse coletivo, conforme definidos em lei.

Do ponto de vista jurídico, se as empresas públicas e sociedades de economia mista atuarem no domínio econômico, não poderão gozar de privilégios fiscais não extensíveis aos demais integrantes do setor privado, para estímulo da concorrência. Não obstante, deve-se ressaltar que há a possibilidade do monopólio em tais atividades, caso em que, por questões estratégicas, haverá supressão da concorrência.

Alerta, contudo, Eros Grau (2006, p. 140) que monopólio não se confunde tecnicamente com serviços públicos, pois a área do monopólio é justamente a atividade econômica em sentido estrito, ao passo que os serviços públicos são considerados um regime de privilégio, por não se enquadrarem no campo de atividades livres ao mercado.

Até o movimento de privatização em larga escala dos anos noventa, tal classificação auxiliava a delimitar os fundamentos da regulação da atividade econômica, que se dava de forma mais intensiva no âmbito dos serviços públicos por conta das características do planejamento exercido pelo Estado (como agente normativo e regulador da atividade econômica), sendo este considerado constitucionalmente determinante para o setor público.

Para o setor privado, o planejamento da regulação deveria ser realizado de forma indicativa. A opção pela economia de mercado, que compreende a valorização da livre-iniciativa, assegura às organizações particulares maior liberdade no planejamento de suas atividades econômicas, pois a chamada economia "descentralizada" garante, em tese, uma maior liberdade de decisão e, consequentemente, de formação dos preços.

Ressalte-se que, via de regra, a tendência é o respeito maior à liberdade de formação dos preços em momentos de estabilidade econômica. Aliás, nos momentos de crise econômica e financeira, em geral, cresce em importância a atividade interventiva do Estado no domínio econômico, que pode ser feita, por exemplo, para regular preços e normalizar o abastecimento.

Segundo expõe Maria Paula Dallari Bucci (2002, p. 1), a chamada Era de Ouro, que seriam os trinta anos de crescimento da economia capitalista que se seguiram à Segunda Guerra Mundial, foi interrompida por dois choques do Petróleo, de 1973 e 1979. Tais choques anteciparam uma discussão recorrente sobre escassez, principalmente de recursos naturais, no mundo. 
A década de oitenta foi, nesta perspectiva, um momento de redefinição do papel do Estado pelos países centrais, a partir de um conjunto conhecido de reformas que impuseram aos países periféricos a desregulamentação do mercado, a abertura comercial e financeira e a redução do tamanho e do papel do Estado (STIGLITZ, 2002, p. 82).

No Brasil, esta influência foi sentida do ponto de vista jurídico com maior intensidade na segunda metade da década de noventa, sendo sua expressão mais evidente extraída do projeto contido no Plano Diretor de Reforma do Aparelho do Estado, sendo tal orientação também refletida no Programa Nacional de Desestatização (Lei nR" 9.494/97). O contexto histórico de crise econômica e de consequente ajuste fiscal foi utilizado como justificativa para a tentativa de redefinição do papel do Estado por meio da Reforma Administrativa dos anos noventa (NOHARA, 2012).

Deste cenário, surgiu o fenômeno da agencificação, paralelamente ao incremento de propostas "descentralizantes" do Estado. A Administração Pública passou a ser influenciada por um vocabulário presente na governança corporativa porque, no fundo, eram os organismos financeiros internacionais que procuravam delimitar condições aos países periféricos para concessão de investimentos, empréstimos e redefinição de parâmetros de endividamento.

Também houve influência do ideário da New Public Management na sua primeira fase de gerencialismo, sendo o Estado confrontado com propostas de flexibilização do regime jurídico público (privatização do público).

Inverteu-se o polo da estatização, que vigorou com distintas intensidades nas décadas de sessenta e setenta no Brasil, para o polo da privatização, sendo este termo tomado tanto em seu sentido restrito, dada, por exemplo, a venda de diversas estatais, como em seu sentido amplo, que, segundo Maria Sylvia Zanella Di Pietro (2011, p. 8), compreende também a intensificação da prestação indireta de serviços públicos pela via da "contratualização" com o setor privado.

Ao Estado são reconhecidos distintos graus de regulação, em função da especialização promovida em diversos setores da economia. Tem-se que diferenciar, portanto, agências (em sentido amplo) que já existiam antes do movimento de Reforma do Estado, pois, não obstante não terem o formato de autarquia em regime especial nos mesmos moldes das atuais agências reguladoras, ainda assim regulavam a atuação do mercado por meio do exercício do poder de polícia, isto é, editando parâmetros normativos que condicionavam ou restringiam as atividades do mercado, das que surgiram 
para ganhar atribuições de Poder Concedente, conforme se ampliava a contratualização nos serviços públicos.

De acordo com Di Pietro (2014, p. 541), enquanto as agências reguladoras que realizavam atividades de poder de polícia já existiam, como ocorria com as atribuições do Cade, do CMN e da Anvisa, as novas modalidades criadas no Brasil no final da década de noventa e no início do século XXI são as que ganharam as atribuições de controle ou fiscalização das delegações de serviços públicos a particulares, tendo sido inspiradas nas agências norte-americanas.

Elas passam a ter, portanto, função de estruturar os investimentos privados em infraestrutura, por meio da elaboração dos editais de licitação, estabelecimento do valor da tarifa, bem como dos critérios de reajuste e celebração de contratos, fixação das regras, portanto, das delegações, controle do desempenho das atividades, aplicação de sanções, rescisão ou alteração unilateral de contratos, acumulando também o papel de ouvidoria da reclamação dos usuários.

Existem, em suma, fundamentos jurídicos subjacentes às práticas de regulação, dada necessidade de conhecimento não só de fatores interdisciplinares, com um enfoque econômico, mas também de limites e possibilidades decorrente do regime das licitações e contratos, que são os institutos veiculadores das condições de prestação dos serviços delegados à iniciativa privada.

Logo, a gestão deve ser feita em função das possibilidades das leis de concessões, seja a Lei Geral (Lei n. 8.987/95), sejam diplomas específicos, como, por exemplo, a Lei das Parcerias-Público Privada (Lei nR" 11.079/ 04), que compreende duas modalidades especiais de concessão (patrocinada e administrativa), sendo de suma importância para a delimitação da política tarifária, bem como da exigência de uma prestação regular dos serviços públicos, a garantia dos objetivos de universalização e de modicidade das tarifas.

\section{CRISE E ESCASSEZ: DISSOLUÇÃO DAS FRONTEIRAS ENTRE PÚBLICO E PRIVADO}

Tendo em vista o fato de que o Estado é permanentemente "desafiado" com metas de ajuste financeiro, cada vez mais as agências procuram conhecer o mercado de fornecedores para fazer planos de outorga e/ou delegação 
mais competitivos. A análise da concorrência é, portanto, uma preocupação deslocada do campo do livre mercado, sendo incorporada recentemente com uma maior intensidade na seara dos serviços públicos, à medida que o Estado se retrai na prestação direta.

Por outro lado, enfatiza Calixto Salomão Filho (2011) que, dada realidade mundial de crise e de crescente escassez, tendo em vista a ampliação do mercado consumidor em cerca de sete bilhões (estima-se que em 2050 seja atingido o número de nove bilhões), tal fenômeno provoca a necessidade de transformação da regulação no mercado, que antes era feita somente para organizar as trocas, ou seja, para aperfeiçoar o funcionamento das atividades econômicas em sentido estrito, mas que passa doravante a ser permeada por preocupações equitativas, focadas em medidas para evitar a assimetria do mercado.

Tendo em vista fatores como: a heterogeneidade de poderio econômico dos agentes, a escassez de recursos, dentre eles, os recursos naturais, e a necessidade de estímulo da disponibilidade de infraestrutura, com metas de ajuste fiscal para o Estado, as agências preocupam-se cada vez mais com as condições isonômicas da concorrência.

Para proceder a tal análise, são utilizadas teorias como a essencial facilities doctrine (teoria de acesso a bens essenciais), com vistas a evitar a necessidade de se duplicar uma rede ou a infraestrutura, como ocorre nas ferrovias. Neste caso, o compartilhamento acaba sendo apresentado como uma solução mais sustentável, inclusive para combater a dominação do mercado, o que prejudica os consumidores.

Calixto Salomão Filho (2006, p. 160) menciona, ainda, o acesso necessário de alguns agentes ("players"/entrantes) para que haja o estabelecimento de preços em níveis concorrenciais, havendo formas mais 'descentralizadas' de se induzir o mercado neste âmbito. Em suma, a questão da eficiência dos setores, também no âmbito privado, passa a ser equacionada em função de fatores sociais de regulação, a depender das características do setor de mercado regulado.

Trata-se de movimento que torna, portanto, indistinta a fronteira entre um regime (dos serviços públicos) que era essencialmente público e um regime de regulação sobre o mercado, sobretudo diante do fato de que em um cenário de maior instabilidade e escassez, também as atividades econômicas em sentido estrito passam a ser alvo de intensiva intervenção estatal. 
Ainda, no âmbito das concessões e permissões, os novos regimes de licitação, seja por meio das parcerias público-privadas ou pela contratação integrada (do regime diferenciado de contratação - RDC), acabam sendo influenciados por uma ótica gerencial de performance, tendo em vista a flexibilização de controles prévios e concomitantes, o que, em inúmeros contextos, acaba distanciando o Estado das decisões mais estratégicas da gestão, sendo o sucesso do contrato mensurado sobretudo com base no cumprimento de metas de desempenho.

A substituição da gestão pública, antes vista como uma atividade ligada aos fins, e a sua "entrega" nas mãos da iniciativa privada provoca a retração do Estado no controle dos serviços públicos, o que acaba mitigando a orientação constitucional de que o planejamento estatal neste âmbito deve ser determinante, conforme previsão do art. 174, caput, da Constituição. Paradoxalmente, diversos setores da iniciativa privada, num cenário de permanente crise e escassez, acabam sendo progressivamente controlados pelo Estado.

Neste contexto, há distintas interpretações. Existem desde os que, a exemplo de Floriano de Azevedo Marques Neto (2002, p. 22), parecem estar otimistas com tal movimento, pois enxergam na superação da dicotomia entre publico/privado uma perspectiva de "republicização", até os que apresentam uma visão mais crítica (e cética) com relação a essas transformações.

Do ponto de vista otimista, pode-se dizer que a retirada do Estado do monopólio da governação provoca o direcionamento ao papel de articulador de compromissos sociais e garantidor do diálogo transparente na arena pública, cumprindo à sociedade civil a conquista de alternativas democráticas de interlocução nesse processo, que pode ser produtivo não apenas para conter o autoritarismo político-estatal, mas sobretudo para restringir as medidas do mercado que se articulam na contramão dos interesses coletivos e que são passíveis de limitação através da atividade intervencionista do Estado.

No entanto, também não se pode ignorar a advertência feita por Gilberto Bercovici, no sentido de que os movimentos de privatização da década de noventa foram, em grande parte, consequência de uma postura "entreguista" dos interesses nacionais ao capital estrangeiro, sendo a desregulamentação propugnada na época prejudicial ao projeto constitucional de desenvolvimento do País.

Nesta perspectiva, cumpre mencionar que a concepção de Gilberto Bercovici acerca de desenvolvimento é noção que transcende a mera 
pretensão de modernização do País, pois modernização pode ocorrer sem que haja melhoria nas condições de vida da população, sendo a maioria alijada dos benefícios ocasionados pela infraestrutura atual.

Vale mencionar, neste ponto, as ideias de Celso Furtado expressadas por Bercovici, in verbis:

Quando não ocorre nenhuma transformação, seja social, seja no sistema produtivo, não se está diante de um processo de desenvolvimento, mas da simples modernização. Com a modernização, mantém-se o subdesenvolvimento, agravando a concentração de renda. Ocorre a assimilação do progresso técnico das sociedades desenvolvidas, mas limitada ao estilo de vida e aos padrões de consumo de uma minoria privilegiada. Embora possa haver taxas elevadas de crescimento econômico e aumentos de produtividade, a modernização não contribui para melhorar as condições de vida da população (BERCOVICI, 2005, p. 53).

Imprescindível acrescentar que as mesmas preocupações, com substrato furtadiano desenvolvimentista, foram externadas pelo próprio Bresser Pereira, que, não obstante ter sido o Ministro da Administração Federal e Reforma do Estado, criticou o modelo de dependência associada empregado na segunda metade dos anos noventa, que tomava as multinacionais como fontes do desenvolvimento brasileiro, a partir da constatação da "desmoralização ideológica globalista que caracterizou os 30 anos neoliberais do Capitalismo (1979-2008) - uma ideologia que condenava o nacionalismo dos países em desenvolvimento enquanto os países ricos praticavam sem hesitação seu próprio nacionalismo" (BRESSER-PEREIRA, 2010, p. 21).

Uma Reforma Administrativa, a nosso ver, não deveria ser um meio apto a subverter as missões constitucionais, pois o papel do Estado está enunciado na Constituição, sendo orientado também aos objetivos de construir, conforme se extrai do art. 3R" da Lei Maior: uma sociedade livre, justa e solidária; garantir o desenvolvimento nacional; erradicar a pobreza e a marginalização e reduzir as desigualdades e promover o bem de todos, sem preconceitos ou outras formas de discriminação.

Ainda, nos anos 2008-2012 houve uma das maiores crises financeiras vivenciadas pelos Estados Unidos desde a Grande Depressão, o que provocou a necessidade de reflexão sobre a delimitação de regras mais claras de governança, sobretudo no setor privado. 
Esse cenário contribuiu para a discussão de novos parâmetros de governança também no setor público, mas enquanto a governança corporativa é uma realidade própria de empresas com capital aberto e que, portanto, dependem de seus investidores, por isso a preocupação de transparência no conflito de interesses (disclosure) entre acionistas, responsabilidade e accountability (prestação de contas), o bom gestor público, por sua vez, é acima de tudo aquele que busca melhor atingir os interesses públicos, caso o princípio da soberania popular não seja considerado mero expediente retórico.

A substituição do gestão burocrática monológica para um gerenciamento mais participativo e dialógico é, conforme expõe Luciana Ronconi, pauta de uma governança pública (RONCONI, 2011, p. 28) mais atualizada. A operacionalização do princípio democrático dá-se, consequentemente, com ações transparentes e compartilhadas, o que reforça a participação dos atores sociais nos processos decisórios públicos e nas formulações das políticas públicas.

No caso brasileiro, há perspectivas de avanço com a edição dos recentes diplomas legislativos: a Lei de Acesso à Informação e a criação da Lei Anticorrupção, que contribuem para se evitar a formação distorcida de preços e, no caso das licitações, por exemplo, coibir práticas que visem a: frustar o caráter competitivo do certame; afastar concorrente em licitação por oferecimento de vantagem ou fraude, criar pessoa jurídica de modo fraudulento ou irregular para participar de licitação, modificar de modo fraudulento os contratos celebrados, manipular o equilíbrio econômicofinanceiro dos contratos; e intervir dificultando a investigação ou fiscalização do Poder Público, seja nas agências reguladoras ou nos órgãos de fiscalização do sistema financeiro nacional.

A Lei Anticorrupção causou um impacto nas práticas empresariais, pois as sanções previstas variam muito, sendo as mais pesadas, por exemplo, a multa, que pode atingir até $20 \%$ do faturamento bruto, e a dissolução compulsória de atividades.

Ademais, o art. 7R", VIII, da Lei nR" 12.846/2013, determina que na aplicação das sanções as autoridades levarão em conta a "existência de mecanismos e procedimentos internos de integridade, auditoria e incentivo à denúncia de irregularidades e a aplicação efetiva dos códigos de ética e de conduta da pessoa jurídica".

Tendo em vista tal previsão, as empresas começaram a estruturar regras mais precisas de compliance (conceito de governança corporativa que 
demanda da empresa que esteja em conformidade com regramentos externos e internos, com introjeção de valores organizacionais nas práticas corporativas). Hoje os códigos de ética passam a ser parte tanto da cultura organizacional pública, como privada.

\section{ABERTURA DOS CANAIS DE INTERLOCUÇÃO NA ATIVIDADE REGULATÓRIA}

Como contra-ofensiva à privatização do público, há então a possibilidade de disseminação de oportunidades de interlocução comunitária no seio das agências reguladoras. Num contexto em que há maiores complexidades dos assuntos regulados, não se admite que a discricionariedade afaste do público a interlocução sobre os interesses públicos subjacentes, para evitar a captura regulatória.

Deve-se advertir também que a regulação econômica sempre existiu e que há, reitere-se, uma maior legitimação do intervencionismo estatal nos períodos de crise. Por exemplo, nos Estados Unidos, pode-se mencionar as medidas intervencionistas de Roosevelt, que tiraram o País da Grande Depressão, e, mais recentemente, na crise de 2008-2012, as medidas foram tamanhas que culminaram inclusive na decisão de o governo adquirir, em 2009, cerca de $60 \%$ do controle acionário da GM, tendo injetado patrimônio público para o resgate da empresa, cuja quebra afetaria a economia norte-americana. Depois de saneada, grande parte das ações adquiridas foram vendidas.

Não se trata, a nosso ver, de uma opção estatizante, muito menos socializante, trata-se do conhecido capitalismo de Estado para a salvaguarda do sistema em relação aos efeitos da crise. Por conseguinte, a regulação deve se voltar à preocupação com a equidade, em que o Estado assume o compromisso constitucional de harmonizar as atividades privadas com o projeto de desenvolvimento sustentável do País, conforme reza, em nosso caso, o art. 219 da Constituição: "o mercado integra o patrimônio nacional e será incentivado de modo a viabilizar o desenvolvimento cultural e socioeconômico, o bem-estar da população e a autonomia tecnologia do País, nos termos da lei federal".

Logo, a preocupação com a assimetria na regulação faz parte do desígnio constitucional de incentivar o mercado, entre outros objetivos, à promoção de objetivos socioeconômicos e de bem-estar geral. 
A partir do compartilhamento de rede e do auxílio dado aos agentes, é possível incentivar a solidariedade social, não de forma ingênua, evidentemente, pois os segmentos privados irão atuar em função de seus objetivos lucrativos imediatos, mas por meio de uma razoável função interventiva estatal, que atinge sobretudo a área de regulação da atividade econômica.

Critica-se, no entanto, os moldes gerenciais expostos no Plano Diretor de Reforma do Aparelho do Estado, com influência na primeira fase da $\mathrm{New}$ Public Management. Conforme expõe Emerson Gabardo (2002, p. 67), a real preocupação do modelo gerencial concentrou-se no ajuste do déficit público com a finalidade de controle inflacionário, sendo todas as outras finalidades meramente acessórias ou simbólicas para legitimar a finalidade principal.

Também a comunidade acadêmica norte-americana já se indaga sobre se as promessas do eixo norte realmente trouxeram tantos avanços aos países periféricos. Por exemplo, os países do chamado eixo norte prometeram a disseminação dos direitos humanos, do devido processo, a eliminação da discriminação e a proteção dos vulneráveis, o desenvolvimento econômico e a proteção do comércio internacional, a partir da restrição da ganância econômica por meio da disseminação da dignidade humana, mas ainda hoje seus críticos observam, conforme temática do Law and Society de 2015, encontro de Seattle (Law's Promise and Law's Pathos in the Global North and Global South), que a lei é praticada como instrumento de repressão e de controle, ou seja, como instrumento de dominação e, no fundo, de recuo do ingrediente político da transformação.

Por conta disso, propugna-se ao invés de um modelo gerencial, adotarse uma burocracia reflexiva (NOHARA, 2014, p. 310), que leve em consideração que um desenvolvimento sustentável é aquele que se orienta democraticamente ao planejamento das políticas públicas, rumo a uma efetiva modificação das estruturas econômicas e sociais, pois somente assim será possível harmonizar a pretensão de modernização da Administração Pública com o objetivo constitucional de desenvolvimento do País.

A reflexividade da burocracia implica, portanto, aprofundar o contato com a sociedade civil por meio de uma noção bem compreendida de consensualidade. A Administração Pública deve ampliar os mecanismos de interlocução comunitária existentes para que haja uma ação mais legítima. Há, entretanto, setores que se aproveitam da ambiguidade da expressão 
consensualidade para fazer valer significações que nem sempre são afinadas com as concepções emancipatórias da cidadania.

Os significados conservadores procuram confundir o intérprete, reputando consensual uma ação do Poder Público acordada diretamente com os setores interessados, o que seria do ponto de vista democrático apenas um "simulacro de consensualidade", pois se toma por pressuposto a adoção de valores consensuais próprios ao universo privado, sem considerar o compartilhamento público deste mesmo consenso.

Por outro lado, significações emancipatórias são as que estimulam o diálogo, que alguns autores chamam de burocracia dialógica (FREITAS, 2004, p. 34), abrindo as instâncias organizacionais a maior e melhor participação pública, mediante a realização de audiências, consultas populares ou qualquer outro meio de influência da cidadania "desinteressada" (na verdade: interessada tão-somente na discussão acerca do bem-estar comum, como, por exemplo, da saúde pública ou da preservação do meio ambiente, e não nos interesses particulares mais imediatos) em assuntos de relevância pública.

Como as medidas tomadas pelo Estado acabam por repercutir no cotidiano dos cidadãos, imprescindível que os debates sejam feitos não apenas no momento das eleições, mas que haja o arejamento das ações administrativas com a participação dialogada (movimento arejado com a proposta de processualização do agir administrativo) e com a consideração pelos argumentos apresentados também pela coletividade.

\section{CONTROLE DA RAZOABILIDADE NA REGULAÇÃO E ESTADO DEMOCRÁTICO DE DIREITO}

Do ponto de vista do conteúdo da regulação, faz-se necessário intensificar a indagação acerca da razoabilidade. Esta deve ser averiguada não em função de regras estanques, até porque cada setor apresenta suas particularidades, mas por standards contextualizados de regulação.

Razoabilidade indica a qualidade de razoável, adjetivo de raiz latina, derivado da palavra razão (ratio). Trata-se de termo com diversos significados, dentre os quais se destacam: logicamente plausível, racional, aceitável pela razão, ponderado e sensato.

Apesar da ausência de previsão expressa da razoabilidade na Constituição, alguns autores (CASTRO, 2006, p. 9) consideraram que ela 
está implícita no art. 5R", LVI, da Lei Maior, que determina que "ninguém será privado da liberdade ou dos bens sem o devido processo legal".

Enquanto o sentido adjetivo do devido processo legal demanda o respeito a garantias individuais, a noção de devido processo legal substantivo (substantive due process) é associada também com a proporcionalidade, sendo esta considerada na Alemanha e em Portugal uma exigência pressuposta no Estado Democrático de Direito.

Canotilho equipara o conceito de proporcionalidade ou de proibição do excesso alemão com o conceito inglês de reasonableness (CANOTILHO, 2004, p. 272). A noção de proporcionalidade exige a relação de causalidade entre os meios e fins, sendo geralmente desdobrada em três elementos: (1) adequação ou pertinência do meio em relação ao fim visado; (2) necessidade da medida, que não pode exceder os limites indispensáveis à conservação do fim que almeja alcançar; e (3) proporcionalidade em sentido estrito.

Excesso de restrição na atividade regulatória tem potencial de aniquilar direitos e, consequentemente, comprometer a própria noção do Estado Democrático de Direito, sendo papel daquele que edita o ato normativo no exercício do poder de polícia compatibilizar as ações políticas do Poder Público com os direitos assegurados constitucionalmente.

Por conseguinte, faz parte da democratização da atuação regulatória estatal, do ponto de vista material, exigir das agências que editam atos normativos que optem por discrimes/critérios menos gravosos às liberdades para o alcance dos objetivos contemplados nas orientações políticas setoriais, o que, segundo o parecer $n R$ " 51 da AGU, deve ser feito a partir das determinações dos Ministérios Supervisores.

A exigência de equilíbrio no poder de polícia era reconhecida nos Tribunais Superiores brasileiros desde a década de sessenta no Brasil, tendo em vista o conteúdo das seguintes súmulas do Supremo Tribunal Federal, ainda hoje em vigor: (a) Súmula 70, de 1963, "é inadmissível a interdição de estabelecimento para a cobrança de tributo"; (b) Súmula 323, de 1963, "é inadmissível a apreensão de mercadorias como meio coercitivo para pagamento de tributos", e (c) Súmula 547, de 1969, "não é lícito à autoridade proibir que o contribuinte em débito adquira estampilhas, despache mercadorias nas alfândegas e exerça suas atividades profissionais".

Ainda, quanto mais democrática for a ambiência institucional vivida, maior será a abertura para o questionamento da razoabilidade dos atos estatais. 
Pode-se dizer, portanto, que a indagação sobre a razoabilidade dos atos de regulação é condizente com a democracia, pois ela abre aos intérpretes a oportunidade de discutir as razões e os motivos subjacentes aos atos restritivos estatais, envolvendo o questionamento sobre se eles são adequados às finalidades objetivadas.

Também a utilização da razoabilidade é especialmente profícua no contexto em que os princípios liberais de mercado são mitigados por outros princípios que traduzem a necessidade por um regime de caráter mais intervencionista, tais como: a função social da propriedade, a defesa de concorrência, a preservação ambiental, bem como as preocupações legítimas de caráter social, como, por exemplo, a busca do pleno emprego (NOHARA, 2006, p. 190).

\section{CONSIDERAÇÕES FINAIS}

Observa-se, conforme exposto, uma alteração substancial na dinâmica da sistemática constitucional sobre a atividade econômica, sendo que a dissolução das fronteiras entre público e privado, num contexto de crise e escassez, provoca a intensificação da regulação na seara do mercado (poder de polícia), imprimindo, por outro lado, aspectos de concorrência no âmbito da prestação de serviços públicos delegados.

Esse fenômeno pode ser desdobrado, portanto: de um lado, na publicização do privado, pois o planejamento começa a não ser meramente "indicativo" do setor, como desejava o Constituinte, e, de outro, numa privatização do público, dada necessidade de as agências procurarem incentivar a concorrência a partir do oferecimento, ao mesmo tempo, de negócios atrativos aos delegatários dos serviços públicos, sendo, ainda, tal corrente intensificada pela tentativa de flexibilização do regime público.

A contra-ofensiva ao movimento da privatização do público, no entanto, pode se dar por meio da abertura dos canais de expressão e de discussão do interesse público no seio das agências reguladoras, trazendo para a atividade regulatória o princípio da soberania popular como uma tentativa de mitigar a ocorrência de captura do setor regulado pelos interesses exclusivos do mercado.

Além do maior estímulo à realização de audiências e consultas populares, também é relevante, para intensificação do princípio democrático, que haja abertura para o questionamento da razoabilidade do conteúdo da 
regulação, para que não haja medidas excessivamente gravosas às atividades econômicas, sendo este um requisito derivado da cláusula do devido processo legal substantivo, conforme visto.

Entende-se, pois, que esses representam alguns caminhos de participação da sociedade na delimitação do conteúdo da regulação, dentro das limitações de assimetria já existentes, pois a regulação, num contexto de escassez, pode ser feita com base em preocupações sociais e de equilíbrio, o que provoca a utilização de mecanismos como o compartilhamento das redes e a intervenção que dê acesso e estímulo a novos atores/players econômicos.

A governança pública, num contexto de Estado Democrático de Direito, que valoriza a noção de soberania popular, deve incorporar nas preocupações sobre o desempenho ou eficiência de dados setores econômicos também a satisfação das necessidades coletivas, sendo este o interesse público primário a ser justificado em atividades de regulação, que representam desdobramentos do poder de polícia em seu sentido amplo.

\section{REFERÊNCIAS}

\section{BANDEIRA DE MELlO, Celso Antônio. Curso de direito} administrativo. 31. ed. São Paulo: Malheiros, 2014.

BERCOVICI, Gilberto. Constituição econômica e desenvolvimento: uma leitura a partir da Constituição de 1988. São Paulo: Malheiros, 2005.

BRESSER-PEREIRA, Luiz Carlos. Nacionalismo, liberalismo e capitalismo. Folha de São Paulo, São Paulo, 1 ago. 2010. Caderno Mundo, p. 21.

BUCCI, Maria Paula Dallari. Direito administrativo e políticas públicas. São Paulo: Saraiva, 2002.

CANOTILHO, José Joaquim Gomes. Direito constitucional e teoria da constituição. Coimbra: Livraria Almedina, 2004.

CASTRO, Carlos Roberto Siqueira. O devido processo legal e os princípios da razoabilidade e da proporcionalidade. Rio de Janeiro: Forense, 2006. 
DI PIETRO, Maria Sylvia Zanella. Direito administrativo. 27. ed. São Paulo: Atlas, 2014.

2011.

. Parcerias na administração pública. 8. ed. São Paulo: Atlas,

FREITAS, Juarez. O controle dos atos administrativos. 3. ed. São Paulo: Malheiros, 2004.

GABARDO, Emerson. Princípio constitucional da eficiência administrativa. São Paulo: Dialética, 2002.

GRAU, Eros Roberto. A ordem econômica na Constituição de 1988. São Paulo: Malheiros, 2006.

MARQUES NETO, Floriano Peixoto. Regulação estatal e interesses públicos. São Paulo: Malheiros, 2002.

NOHARA, Irene Patrícia. Limites à razoabilidade nos atos administrativos. São Paulo: Atlas, 2006.

. Burocracia reflexiva. In: MARRARA, Thiago (Org.). Direito administrativo: transformações e tendências. São Paulo: Almedina, 2014. p. 349-372.

. Reforma administrativa e burocracia: impacto da eficiência na configuração do direito administrativo brasileiro. São Paulo: Atlas, 2012.

RONCONI, Luciana. Governança pública: um desafio à democracia. Emancipação, Ponta Grossa, v. 11, n. 1, p. 21-34, 2011.

SALOMÃO FILHO, Calixto. O novo direito societário. 3. ed. São Paulo: Malheiros, 2006.

. Regulação assimétrica exige o compartilhamento de bens. 2011. Disponível em: <https://www.youtube.com/watch?v=o0f5gt6v6r4>. Acesso em 2 de out. 2014. 
STIGLITZ, Joseph. A globalização e seus malefícios: a promessa não cumprida de benefícios globais. São Paulo: Futura, 2002.

Submetido em: 03/12/2014 Aprovado em: 16/03/2015

Como citar: NOHARA, Irene Patrícia. Regulação da atividade econômica na dissolução das fronteiras entre público e privado. Scientia Iuris, Londrina, v19, n.1, p.29-46, jun.2015. 